\title{
Optimal dispatch of electricity storage supporting the direct supply of industrial consumers by wind generation
}

\author{
Eva Schischke', and Clemens Grimpe ${ }^{1}$ \\ ${ }^{1}$ Fraunhofer Institute for Environmental, Safety, and Energy Technology UMSICHT, 46047 Oberhausen, Germany
}

\begin{abstract}
A rising number of industrial companies are aiming to increase the share of renewable generation in their electricity consumption, in order to decrease electricity costs or to fulfill portfolio requirements. This can be achieved by using pv or wind generation systems, which are directly connected to the industrial consumer. The volatility of the renewable generation can be balanced by employing an electricity storage system. The paper presents an MILP optimization model for the direct supply of an industrial consumer by a wind farm, coupled with a storage system. The model optimizes the dispatch of the storage system in order to minimize both the energy component as well as the capacity component of the consumers electricity cost. A case study is presented using the grid tariffs in Germany for two different legal scenarios and two load profiles. The operation of a modular compressed air energy storage system is analyzed and the optimal dimensions of the storage power and capacity are determined, for the proposed system.
\end{abstract}

\section{Introduction}

A rising number of industrial customers are aiming to increase the share of renewable generation in their electricity consumption, in order to decrease electricity costs or to fulfil portfolio requirements [1]. Concurrently, wind power producers are looking for new ways to sell their energy generation, after the termination of feed-in tariffs. One possibility are power purchase agreements (PPA), which are concluded directly between customer and producer [1]. In order to match the renewable generation and the customers demand more effectively, electricity storage systems can be employed. However, there is no quantification of the customer benefit of the storage operation as well as guidelines for optimal storage system dimensions. Therefore, the authors introduce these analyses based on a case study for Germany in this paper.

In the literature, PPAs are mostly just one possibility among several, when analysing the energy procurement of large customers from different sources. The focus is on the optimal energy portfolio of the customer and not on the configuration of the PPA, e.g. [2-4].

This paper focuses on the PPA and especially on the operation of the storage coupled with the renewable generation. A mathematical model minimizes both the energy component as well as the capacity component of the consumers electricity cost by employing the storage system.

In [5], the feasibility of supplying an industrial water treatment plant by renewable generation is analysed.
The results are obtained using the HOMER model, but no emphasis is put on the optimal storage dispatch. In earlier studies [6], a compressed air energy storage (CAES) system is used in a hybrid power plant, but only a simulation is carried out. In contrast to the following studies, the optimal dispatch of the storage system is not considered.

In Chapter 2, the mathematical model is introduced in detail. Subsequently, the authors present a case study for Germany in chapter 3. Referring to this, a modular compressed air energy storage system is coupled with a wind farm in order to supply an industrial customer. The benefit for the customer as well as the optimal dimensions of the storage system are quantified.

\section{Mathematical model}

The following discusses the mixed-integer linear optimization model (MILP), which optimizes the dispatch of the storage system in order to reduce the electricity costs for the consumer. The model is formulated generically to support different types of storage technologies.

\subsection{System configuration}

Fig. 1 shows the system configuration. The system consists of two nodes - one on the generation side and one at the customer site. For both nodes the summed 
power injected into the node has to be equal to the summed power taken from it for each time step.

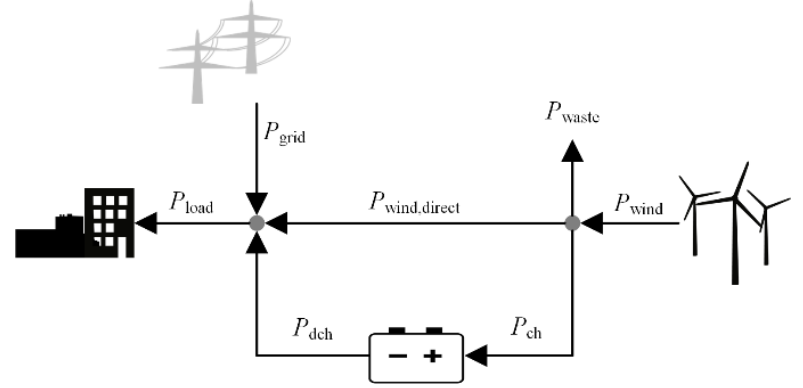

Fig. 1. System configuration for the direct supply of an industrial customer by wind in combination with a storage system

The generation node splits the wind generation in a share going directly to the customer $P_{\text {wind,direct }}$ and a share charging the storage $P_{\mathrm{ch}}$. Any overproduction that cannot be directly used or charged, is termed $P_{\text {waste }}$. However, this does not mean it is literally wasted, but that it is not part of the considerations. The wind farm could still sell this energy to another customer or to the grid.

$$
P_{\text {wind }}(t)=P_{\text {wind,direct }}(t)+P_{\text {ch }}(t)+P_{\text {waste }}(t)
$$

The node on the customer side represents the different ways in which the customer can cover its load. Preferably, it is covered directly by wind generation. If that is not possible, the customer can choose to buy electricity from the grid or to discharge energy from the storage.

$$
P_{\text {wind,direct }}(t)+P_{\mathrm{dch}}(t)+P_{\text {grid }}(t)=P_{\text {load }}(t)
$$

The electricity costs of the customer consist of fees, surcharges, taxes and the acquisition itself. The total energy related costs $C_{\text {energy }}$ are equal to the consumed energy multiplied with the specific electricity price for each type of energy source respectively.

$$
\begin{aligned}
C_{\text {energy }}=\sum_{t=0}^{T} \Delta t & \cdot\left(c_{\text {wind }} \cdot P_{\text {wind, direct }}(t)\right. \\
& +c_{\text {storage }} \cdot P_{\text {dch, } \mathrm{t}}(t) \\
& \left.+c_{\text {grid }} \cdot P_{\text {grid }}(t)\right)
\end{aligned}
$$

In addition, the total electricity costs $C_{\text {total }}$ have a capacity component depending on the peak load taken from the grid.

$$
C_{\text {total }}=C_{\text {energy }}+c_{\text {peak load }} \cdot P_{\text {peak load }}
$$

The costs for the wind generation $c_{\text {wind }}$ and the discharged energy from the storage $c_{\text {storage }}$ are divided into operating costs and cost for the energy transmission. Due to this energy system configuration, all grid-related shares of the energy transmission costs are excluded except for the electricity tax and the renewable energy surcharge.

\subsection{Objective function}

The model optimizes the electricity costs of the customer (s. Eq. (4)) in two consecutive steps.

In the first step, the objective function is equal to the energy costs $C_{\text {energy }}$ in order to minimize the variable costs of the system for one year. The function minimizes the costs for every day of the year in 15-minute intervals with a limited forecast of 12 hours in order to achieve realistic results. The model is subject to constraints implied by the load, the available wind generation and the configuration of the storage as described in chapter 2.3 and chapter 2.4 .

The second step of the optimization is to locate the minimal total costs $C_{\text {total }}$. This is done by imposing a constraint to the maximum power taken from the grid.

$$
P_{\text {load }}(t) \leq P_{\text {peak load, max }}(i)
$$

The maximum peak load is obtained by iteratively lowering it in $i$ discrete steps and repeating the variable cost optimization with this new constraint, until no further reduction of the total costs is achieved.

$$
P_{\text {peak load, max }}(i)=P_{\text {peak load }}-i \cdot \Delta P
$$

\subsection{Storage system}

The model for the electricity storage system is based on [7]. The storage is represented by its current charging and discharging power, as well as its current state of charge $S O C_{\mathrm{t}}$, which are limited by the physical upper and lower limits.

$$
\begin{gathered}
S_{\mathrm{ch} / \mathrm{dch}}(t, n) \cdot P_{\mathrm{ch} / \mathrm{dch}, \min } \leq P_{\mathrm{ch} / \mathrm{dch}}(t, n) \\
\leq P_{\mathrm{ch} / \mathrm{dch}, \max } \\
S O C_{\min } \leq S O C(t) \leq S O C_{\max }
\end{gathered}
$$

The SOC as well as charging and discharging power are linked by a piecewise linear function of the charging and discharging efficiency respectively. The model equations for the efficiency can be found in [7].

The model has the possibility to build several storage systems of the same type as is described in [8] to support modular storage systems. The total storage power is equal to the sum of the individual modules.

$$
P_{\mathrm{ch} / \mathrm{dch}}(t)=\sum_{\mathrm{n}=1}^{\mathrm{N}} P_{\mathrm{ch} / \mathrm{dch}}(t, n)
$$




\subsection{Wind generation}

In the model the current wind velocity $v_{\text {wind }}$ is used to calculate the wind power generation in each time step. Equation (10) shows the correlation between the wind speed and the power output, which depends on the air density at hub height as well as the rotor area.

$$
P_{\mathrm{WT}}=c_{\mathrm{p}} \cdot \frac{1}{2} \cdot \rho_{\mathrm{air}} \cdot A_{\text {rotor }} \cdot v_{\mathrm{wind}}^{3}
$$

The power coefficient $c_{\mathrm{p}}$ is modelled as a look-up table. For wind speeds below the cut-in wind speed and above the cut-out wind speed, the current wind power generation $P_{\mathrm{WT}}$ is zero.

In order to convert the measured wind speed $v_{h 0}$ to the wind speed at hub height $v_{\text {wind,h1 }}$, the log wind profile formula is used (Eq. (11)), with $r$ being the roughness length of the surrounding area.

$$
v_{\text {wind,h1 }}=v_{h 0} \cdot \frac{\ln \left(\frac{h_{1}}{r}\right)}{\ln \left(\frac{h_{0}}{r}\right)}
$$

The total wind power generation is calculated by multiplying $P_{\mathrm{WT}}$ with the number of wind turbines in the analysed scenario.

\section{Case Study}

As a case study the optimal dispatch of a small scale modular compressed-air energy storage system is presented. It is applied to load profiles and weather data in Germany using the German grid tariffs and legal conditions. These are further described in chapter 3.1. chapter 3.2 and chapter 3.3 show the CAES system and the input data respectively. The results of the case study are presented and discussed in chapter 3.4 and 3.5.

\subsection{Electricity costs and legal scenarios}

As described in chapter 2.1 the electricity price for large customers is a combination of different components. Industrial customers in Germany pay $18.55 \mathrm{ct} / \mathrm{kWh}$ for electrical energy in 2020 [9]. This is the price for the energy bought from the grid $P_{\text {grid }}$. The three most significant components of the electricity price are the acquisition and grid fees $(9.27 \mathrm{ct} / \mathrm{kWh})$, the renewables surcharge $(6.756 \mathrm{ct} / \mathrm{kWh})$ and the electricity tax $(1.537 \mathrm{ct} / \mathrm{kWh})$. In addition, the capacity component of $88.78 € / \mathrm{kW}_{\text {peak }}$ has to be paid. Some of these price components can be avoided for the wind generation and discharged energy. For that to be the case several conditions have to be met. Firstly, the wind turbines, the storage system and the customer must be located within a range of $2 \mathrm{~km}$ to each other. Secondly, the public grid may not be used. Thirdly, the customer must have the ownership of the storage system and wind turbines. If in addition only renewable energies are used to charge the

\footnotetext{
* LTA-CAES $^{\circledR}$ is a registered trademark of Fraunhofer UMSICHT. For reasons of readability, the registered sign is omitted in the following.
}

storage, the renewable surcharge for the discharging power can be reduced to $40 \%$ (and in some cases $0 \%$ ), and the electricity tax does not apply [10].

Without employing the wind generation and storage system, the customer has to pay $18.55 \mathrm{ct} / \mathrm{kWh}$ for the entire annual energy consumption (Base Case). If wind energy is used, a part of the energy can be covered by the cheaper wind energy (Base Case + wind). A differentiation is made between two legal scenarios for the storage system usage. In legal scenario 1 (LS 1), the renewable surcharge is avoided completely using wind energy. In legal scenario 2 (LS 2), $40 \%$ of the renewable surcharge must be paid for the discharged energy. The reason for the differentiation are uncertainties in the legal decisions.

Table 1: Electricity prices for the different energy source in $\mathrm{ct} / \mathrm{kWh}$ for two different legal scenarios LS1 and LS 2

\begin{tabular}{lcc}
\hline & LS 1 & LS 2 \\
\hline$c_{\text {grid }}$ & 18.55 & 18.55 \\
$c_{\text {storage }}$ & 0 & 2.71 \\
$c_{\text {wind }}$ & 3.07 & 5.78 \\
\hline
\end{tabular}

\subsection{CAES storage system}

In the project KompEx LTA-CAES ${ }^{\circledR}$ modular $^{*}$ a small, modular adiabatic compressed air energy storage system is developed in order to use the long-term storage capacity of compressed air energy storage systems for a wide range of storage applications. Through the modular design, the storage power can be easily dimensioned to fit the application requirements. Additionally, the combination of turbo and piston machinery makes the storage compatible with a variety of gas storage volumes and allows an independent sizing of the storage capacity. A detailed description of the KompEx LTACAES design can be found in [11].

One module has a charging power of $2.00 \mathrm{MW}$ and a discharging power of $1.39 \mathrm{MW}$. The lower part load limit is 0.55 and 0.49 of the maximum charging and discharging power respectively. The round-trip efficiency of the storage is assumed to be $56 \%$.

\subsection{Load and generation profiles}

For the demand time series as well as the wind speed time series open data is used. The wind speeds and environmental data are for the site Berlin-Tegel, which has average wind speeds in Germany, for the year 2017 [12]. The technical data of the turbine model Enercon E70 is used, as the guaranteed feed-in tariff will terminate 
for many of these turbines within the next few years [13]. In order to fit with the proposed power of the storage system a theoretical site with 5 turbines was chosen. The total power of the wind generation is therefore 11.55 MW. The number of wind turbines was chosen in such a way that the annual wind generation is approximately even to the consumption of the load in one year (ca. 15 million $\mathrm{kWh}$ ).

Different load curves from [14] were analysed and negative values were removed. In order to consider different customer types, two profiles with lower and higher load fluctuations respectively (measured by the relative standard deviation) were selected. These were scaled up so that the average load demand lies between the discharging power of one and two storage modules, which are 2 and $4 \mathrm{MW}$ respectively, in order to see if a slightly smaller or slightly bigger storage power sizing is more advantageous. The naming conventions of [14] were retained with load profile 9 corresponding to the profile with low fluctuations and load profile 21 having higher fluctuations.

Table 2: Overview of the analyzed load profiles

\begin{tabular}{lcc}
\hline & Load profile & Load profile \\
& 91 & 21 \\
\hline Type of customer & Metalworking & Gravel \\
Peak demand & $4,247 \mathrm{~kW}$ & $6,030 \mathrm{~kW}$ \\
$\begin{array}{l}\text { Scale-up factor } \\
\begin{array}{l}\text { relative standard } \\
\text { deviation }\end{array}\end{array}$ & $364 \%$ & $343 \%$ \\
\hline
\end{tabular}

In summary, the scenario analysis includes two legal scenarios for two different load profiles. For each of those scenarios we looked at one and two storage modules and made a sensitivity analysis to find the optimal storage capacity. In the following the storage capacity is given in hours, corresponding to the amount of energy that would have been stored while charging at maximum charging power with an efficiency of $100 \%$ in order retain comparability between different scenarios. The capacity is varied between 4 and 12 capacity hours.

\subsection{Results}

The model yields the annual electricity costs of the customer. The annual electricity costs without wind (Base Case) and with wind generation (Base Case + Wind) for the different load profiles are presented in Table 3.

\footnotetext{
$\dagger$ For the case study an interest rate of $5 \%$ and a project lifetime of 25 years are assumed. The relation between power and capacity capital costs is assumed to be 0.2 .
}

Table 3: Annual electricity costs without storage operation in million $€$ for base case and base case incl. wind generation

\begin{tabular}{lccc}
\hline & Base Case & \multicolumn{2}{c}{ Base Case + Wind } \\
\cline { 2 - 4 } & - & LS 1 & LS 2 \\
\hline Load profile 9 & 2.818 & 1.953 & 2.129 \\
Load profile 21 & 2.818 & 2.013 & 2.191 \\
\hline
\end{tabular}

The annual savings for the storage operation are calculated in comparison to the base case including wind generation (Base Case + Wind) in order to estimate the effect stemming from the storage operation.

Using legal scenario 1 it is possible to save between $115,000 €$ and $330,000 €$ per year by employing the storage system.

In order to find the optimal storage dimensions the concept of additive Break-Even Capital Costs (BECC) is used as introduced in [15]. The BECC assume a fixed relation between power related capital costs and capacity related capital costs. This enables the determination of optimal storage dimensions that depend on the interest rate and lifetime of the project.

The BECC for legal scenario 1 are presented in Fig. 2 for load profile 21 and in Fig. 3 for load profile $9^{\dagger}$.

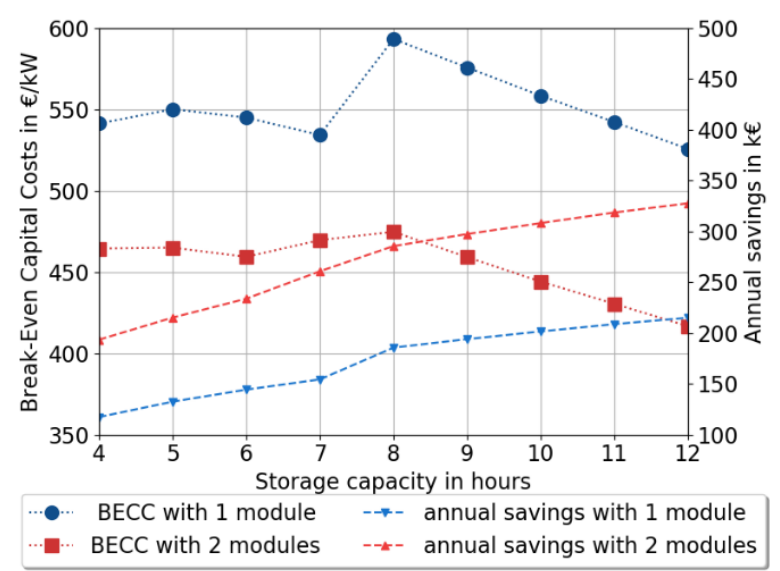

Fig. 2. Specific power related Break-Even Capital Costs and annual savings for load profile 21 in legal scenario 1

Load profile 21 yields higher BECC than load profile 9. However they are in a similar range, between $400 € / \mathrm{kW}$ and $600 € / \mathrm{kW}$. The highest BECC for load profile 21 are $593 € / \mathrm{kW}$ corresponding to $101 € / \mathrm{kWh}$. For load profile 9 the highest BECC are $544 € / \mathrm{kW}$ corresponding to $92 € / \mathrm{kWh}$. The difference stems mainly from the peak load reduction the effects of which are described later. Since load profile 21 is the profile with higher fluctuations and a higher total peak load it is reasonable that the savings caused by the peak load reduction are higher than load profile 9 . 


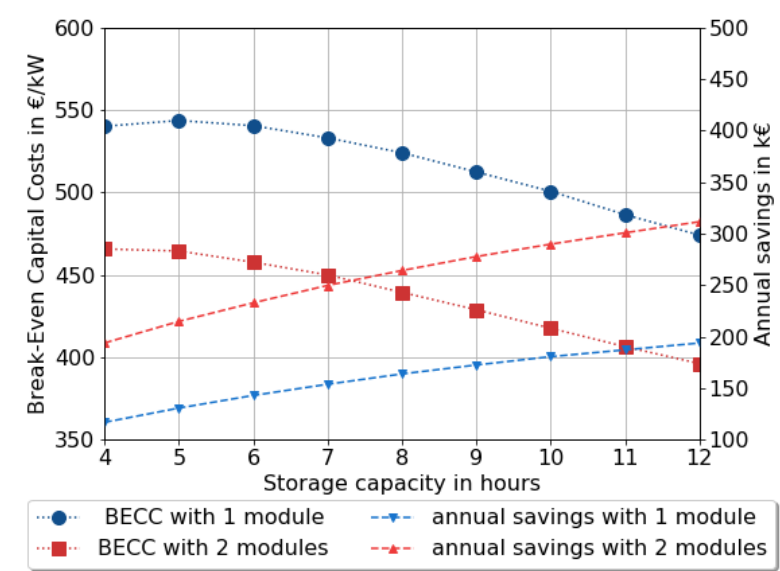

Fig. 3. Specific power related Break-Even Capital Costs and annual savings for load profile 9 in legal scenario 1

Though the annual savings for two modules are higher than for one, employing one module yields higher BECC than two modules for both load profiles.

The optimal storage capacity for load profile 21 is 8 hours while for load profile 9 it is 5 hours. The difference is rooted in the peak load reduction.

For load profile 21 the peak load can be reduced by $4.0 \%$ in two iteration steps. But only for storage capacities of 8 hours and more. Below that, peak load reduction is not possible. This is visible in Fig. 2 at the sharp bend of the curve of the annual savings. This effect is more pronounced for one than for two modules. The reason behind being that for the storage operation with two modules and a storage capacity of seven hours a peak load reduction of $2.0 \%$ is achieved resulting in a less pronounced bend This translates to higher BECC for the storage capacities, where peak load reduction is possible. If only the results without peak load reduction are considered, the optimal dimension for load profile 21 is 5 hours as well.

For load profile 9 , peak load was only reduced by $2.5 \%$, but for the entire range of investigated storage capacities. As a reason of that no bend in the curves can be observed, which leads to the same optimal dimensions as in the case without peak load reduction. These results stem from the way the peak load reduction is modelled in discrete steps. In this particular case the number of iteration steps was very uniform which only leads to a constant parallel shift of the curves.

The peak load reduction results in around $9,200 €$ additional saved annual costs for load profile 9 and around $13,000 €$ additional saved annual costs for load profile 21 in comparison to just lowering the energy consumption.

Legal scenario 2 yields lower annual savings with the highest being around 278,000 $€$ per year. This leads to BECC of $508 € / \mathrm{kW}$ for load profile 21 corresponding to $86 € / \mathrm{kWh}$. For load profile 9 the highest BECC in legal scenario 2 are $473 € / \mathrm{kW}$ corresponding to $80 € / \mathrm{kWh}$.

From Fig. 4 and Fig. 5 it can be seen that the optimal dimension does not change between the legal scenarios. It just influences the absolute value of the annual savings, which are smaller for legal scenario 2 .

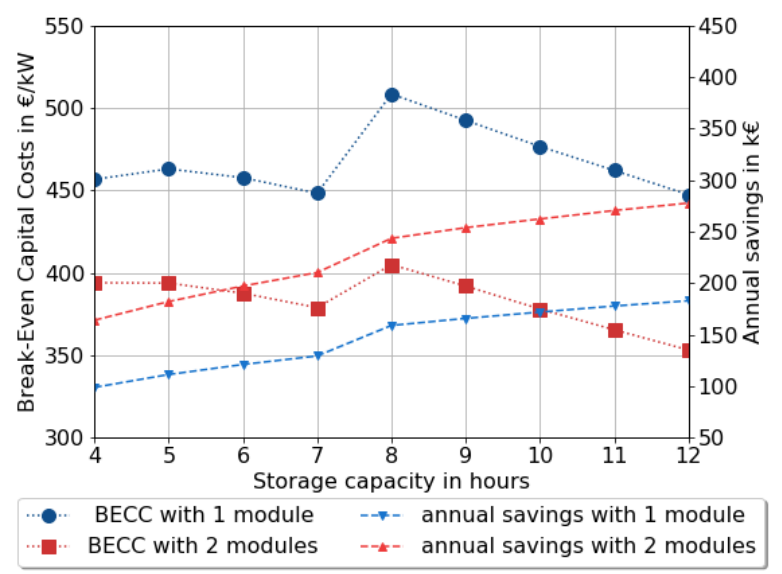

Fig. 4. Specific power related Break-Even Capital Costs and annual savings for load profile 21 in legal scenario 2

As in legal scenario 1 peak load reduction is possible over the entire range of storage capacities for load profile 9 . For load profile 21, peak load reduction is also only possible for storage capacities above 7 hours.

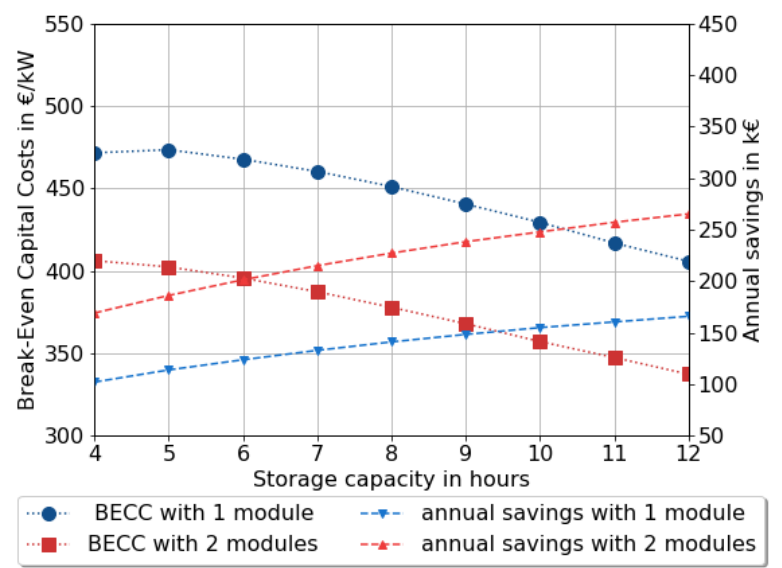

Fig. 5. Specific power related Break-Even Capital Costs and annual savings for load profile 9 in legal scenario 2

\subsection{Discussion}

The results show that it is possible to reduce the electricity costs of the customer significantly. Furthermore, including peak load reduction in the model results in additional value for the storage. In the analysed case study, storage capacities of five and eight hours were optimal. This supports the use of bulk storage technologies such as CAES systems with low specific capacity capital costs.

However, in the presented case study the additional value of the storage operation is not sufficient to support the investment in the storage system. According to literature the additive capital costs for CAES storage systems are currently around $910 € / \mathrm{kW}$ and $204 € / \mathrm{kWh}$ respectively [16]. In comparison, the highest attainable BECC in the presented case study are around $600 € / \mathrm{kW}$ and $100 € / \mathrm{kWh}$.

In contrast, the value of using wind generation is quite high for the customer. As is shown in Table 3 the 
customer can save between 627,000 and $865,000 €$ per year by using wind generation instead of buying the electricity from the grid. This shows that PPAs are a reasonable instrument for selling wind power after the termination of feed-in tariffs. It is however not the focus of this paper and no further conclusions can be drawn from the analysis.

As shown in chapter 3 , the sizing of the wind generation in this case study is illustrative. The wind production was dimensioned to equal the annual consumption of the load and to approximately fit the power dimension of the storage system. In order to support the economics of the storage operation the system configuration could be part of a preceding optimization to properly dimension the wind generation in combination with the storage system as well as the load profile.

\section{Conclusion}

A MILP optimization model for the direct supply of an industrial consumer by a wind farm, coupled with a storage system was presented. Two different legal scenarios and two load profiles were analyzed, and it was shown that a significant reduction of the total electricity costs could be achieved in each. However, the additional value of the storage operation was relatively small compared to the employment of wind generation by itself. The analyzed case studied showed that the optimal dimension of the storage capacity depend on whether or not peak load reduction is possible in the analyzed scenario.

In future work the model could be expanded to include time-dependent variable electricity costs for the energy taken from the grid and using the storage system to offer demand-side management flexibility to the grid by the customer. In addition, direct supply of energy to a customer could be analyzed using the cost function of new wind turbines as well as allowing the wind farm to trade remaining energy at spot markets to create additional value.

The authors thank the German Federal Ministry for the Economic Affairs and Energy for funding the project “KompEx LTA-CAES ${ }^{\circledR}$ modular" (FKZ 03ET6070A).

\section{References}

1. L. Mendicino, D. Menniti, A. Pinnarelli, N. Sorrentino, Applied Energy 253, 113577 (2019)

2. D. Yu, H. liu, C. Bresser, Energy 163, 969 (2018)

3. H. Farham, L. Mohammadian, H. Alipour, J. Pouladi, Solar Energy 174, 923 (2018)

4. F. Angizeh, M. Parvania, IET Renewable Power Generation 13, 2705 (2019)

5. M. Soshinskaya, W.H.J. Crijns-Graus, J. van der Meer, J.M. Guerrero, Applied Energy 134, 20 (2014)

6. V. MARANO, G. RIZZO, F.A. Tiano, Applied Energy 97, 849 (2012)
7. A. Kanngießer, Entwicklung eines generischen Modells zur Einsatzoptimierung von Energiespeichern für die techno-ökonomische Bewertung stationärer Speicheranwendungen (Karl Maria Laufen, Oberhausen, 2014)

8. Eva Schischke, Annedore Kanngießer, Markus Hadam, Marcus Budt, in Proceedings of the 13th International Renewable Energy Storage Conference 2019 (IRES 2019), ed. by Atlantis Press , p. 1

9. BDEW-Strompreisanalyse Januar 2020: Haushalte und Industrie, https://www.bdew.de/media/documents/2020010 7_BDEW-Strompreisanalyse_Januar_2020.pdf (2020)

10. Faktenpapier https://www.bves.de/wp-

Energiespeicher, content/uploads/2017/05/Faktenpapier_2017.pdf (2017)

11. M. Budt, M. Hadam, E. Schischke, in 2019 Offshore Energy and Storage Summit (OSES) (IEEE, 2019 - 2019), p. 1

12. Archiv der Klimadaten Deutschland Stundenwerte-, https://www.dwd.de/DE/leistungen/klimadatende utschland/klarchivstunden.html?nn=16102

13. Onshore Windkraftanlagen in Deutschland, https://opendata-esri-

de.opendata.arcgis.com/datasets/dc6d012f47d94f de99deacc316721f30 0? geometry $=$ $34.021 \% 2 \mathrm{C} 40.840 \% \overline{2 \mathrm{C}} 133.411 \% 2 \mathrm{C} 60.060$

14. J. Huber, K. Nikolai, J. Becker, C. Weinhardt, Electricity consumption of 28 German companies in 15-min resolution, https://publikationen.bibliothek.kit.edu/10000980 27 (2019)

15. A. Kanngießer, Entwicklung eines generischen Modells zur Einsatzoptimierung von Energiespeichern für die techno-ökonomische Bewertung stationärer Speicheranwendungen (Verlag Karl Maria Laufen, Oberhausen, 2014)

16. X. Luo, J. Wang, M. Dooner, J. Clarke, Applied Energy 137, 511 (2015) 